Check for updates

Cite this: RSC Adv., 2018, 8, 3462

\title{
Enhanced electrochemical properties of cerium metal-organic framework based composite electrodes for high-performance supercapacitor application $\dagger$
}

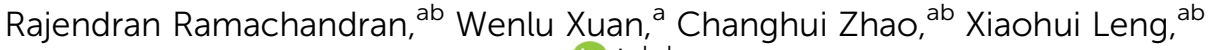 \\ Dazhi Sun, ${ }^{\mathrm{C}}$ Dan Luo ${ }^{\mathrm{a}}$ and Fei Wang (D)*abd
}

Cerium metal-organic framework based composites (Ce-MOF/GO and Ce-MOF/CNT) were synthesized by a wet chemical route and characterized with different techniques to characterize their crystal nature, morphology, functional groups, and porosity. The obtained Ce-MOF in the composites exhibit a nanorod structure with a size of $\sim 150 \mathrm{~nm}$. The electrochemical performance of the composites was investigated in $3 \mathrm{M} \mathrm{KOH}$ and $3 \mathrm{M} \mathrm{KOH}+0.2 \mathrm{M} \mathrm{K}_{3} \mathrm{Fe}(\mathrm{CN})_{6}$ electrolytes. Enhanced electrochemical behavior was obtained for the Ce-MOF/GO composite in both electrolytes and exhibited a maximum specific capacitance of $2221.2 \mathrm{~F} \mathrm{~g}^{-1}$ with an energy density of $111.05 \mathrm{~W} \mathrm{~h} \mathrm{~kg}^{-1}$ at a current density of $1 \mathrm{~A} \mathrm{~g}^{-1}$. The large mesoporous structure and the presence of oxygen functional groups in Ce-MOF/GO could facilitate ion transport in the electrode/electrolyte interface, and the results suggested that the Ce-MOF/ GO composite could be used as a high-performance supercapacitor electrode material.

Received 26th November 2017 Accepted 11th January 2018

DOI: $10.1039 / c 7 r a 12789 h$

rsc.li/rsc-advances with carbonaceous materials. ${ }^{\mathbf{1 1}}$ The synergistic effects of these hybrid electrodes not only have the advantage of the high conductivity and flexibility of carbon materials but also can efficiently utilize the high specific capacitance of the pseudocapacitive elements, thus improving the electrochemical properties. $^{\mathbf{1 2 , 1 3}}$ Therefore it is well recognized that the electrode material is essential when it comes to determining the performance of supercapacitors.

Very recently, metal-organic frameworks (MOFs), as a unique class of energy storage materials, have continuously drawn great interest in the investigation of supercapacitor electrodes due to their large specific surface area, controllable microporous structure and tunable pore size, and incorporated redox metal centers. ${ }^{\mathbf{1 4}, 15}$ MOFs have been employed to supercapacitor electrodes in two ways. First, it could be used directly as an electrode material; and secondly, MOFs derived materials such as metal oxides, nanoporous carbon and their composite materials can be developed. ${ }^{\mathbf{1 6}-18}$ Furthermore, when directly used as electrode materials depending on incorporating pseudocapacitive redox centers, the bare MOFs can allow more active sites and facilitate faster ion transport between electrode and electrolyte. ${ }^{19}$ Up to date, several MOF and MOF derived materials have been studied for supercapacitor applications, such as $\mathrm{Co}^{20}, \mathrm{Zn}^{21}, \mathrm{Ni}^{22}, \mathrm{Cd}^{23}, \mathrm{Mn}^{24}$ and bimetallic like $\mathrm{Co} / \mathrm{Zn}^{25}$, etc. However, the lousy electrolyte flexibility of MOFs and MOFs derived materials may cause the poor stability during charge/ discharge process, which has been considered as a major constraint in supercapacitors. ${ }^{26}$ Fortunately, MOF with carbon 
materials like graphene, graphene oxide and CNT could increase the electrochemical performance for supercapacitors; and therefore, the research direction has been turned to making MOF/carbon composites. ${ }^{27-29}$ Recently, Wen et al., have reported Ni-MOF/CNT composite for supercapacitor applications with the energy density of $36.6 \mathrm{~W} \mathrm{~h} \mathrm{~kg}{ }^{-1} .{ }^{30}$ Saraf et al. ${ }^{31}$ have studied the electrochemical properties of $\mathrm{Cu}-\mathrm{MOF}$ with rGO and reported that the addition of rGO remarkably enhanced the capacitance behavior of $\mathrm{Cu}-\mathrm{MOF}$ with great cyclic stability. The MOF/carbon material combinations not only facilitated the utilization of the active sites during the electrochemical performance but also enhanced the mechanical strength and electrical conductivity synergistically.

Utilization of some redox additives in the electrolyte is another approach to enhance the specific capacitance of electrode materials. The capacitance can increase via redox reactions of the additives between the electrode and electrolyte interfaces. Up to date, there are several types of redox additives like hydroquinone, ${ }^{32}$ iodide, ${ }^{33} \quad m$-phenylenediamine, ${ }^{34}$ $\mathrm{K}_{3} \mathrm{Fe}(\mathrm{CN})_{6}$ (ref. 35) and recently redox-additive polymers ${ }^{36}$ have been reported for supercapacitor applications. The effect of the migration of redox species between electrode and electrolyte interfaces is the primary characteristic to improve the pseudocapacitance and cyclic stability. Among various redox additives, $\mathrm{K}_{3} \mathrm{Fe}(\mathrm{CN})_{6}$ has been identified as an excellent choice because its different oxidation/reduction states can facilitate multiple redox activities during electrochemical process. Besides, the redox pair of $\mathrm{Fe}(\mathrm{CN})_{6}{ }^{3-} / \mathrm{Fe}(\mathrm{CN})_{6}{ }^{4-}$ can decrease the charge transfer resistance of $\mathrm{KOH}$ electrolyte which allows fast electron transportation. ${ }^{37}$

In this paper, we have proposed a room temperature wet chemical synthesis of Ce-MOF/GO and Ce-MOF/CNT composites, and have investigated their electrochemical properties in $3 \mathrm{M} \mathrm{KOH}$ and $3 \mathrm{M} \mathrm{KOH}+0.2 \mathrm{M} \mathrm{K}_{3} \mathrm{Fe}(\mathrm{CN})_{6}$ electrolytes. It has been observed that the presence of GO in Ce-MOF could remarkably improve the specific capacitance and energy density of Ce-MOF rather than CNT. The obtained Ce-MOF/GO composite exhibits a maximum specific capacitance of 233.8 and $2221.1 \mathrm{~F} \mathrm{~g}^{-1}$ in $3 \mathrm{M} \mathrm{KOH}$ and $3 \mathrm{M} \mathrm{KOH}+0.2 \mathrm{M} \mathrm{K}_{3} \mathrm{Fe}(\mathrm{CN})_{6}$ electrolytes, respectively. This fact is due to the pseudocapacitance contribution of oxygen functional groups in GO.

\section{Experiment method}

\section{Materials}

Ceirum(II) nitrate hexahydrate $\left(\mathrm{Ce}\left(\mathrm{NO}_{3}\right)_{2} \cdot 6 \mathrm{H}_{2} \mathrm{O}\right), 1,3,5$-tricarboxylic acid $\left(\mathrm{H}_{3} \mathrm{BTC}\right)$, ethyl alcohol, potassium hydroxide $(\mathrm{KOH})$, potassium hexacyanoferrate(III) $\left(\mathrm{K}_{3}\left[\mathrm{Fe}(\mathrm{CN})_{6}\right]\right)$ were purchased from Sigma-Aldrich. Graphene oxide and carbon nanotube were purchased commercially from XFNANO, China. All the solutions were prepared using Milli-Q water ( $\mathrm{pH}$ 7.2)

\section{Synthesis of Ce-MOF, Ce-MOF/GO and Ce-MOF/CNT}

The Ce-MOF based composites were prepared with little alteration of literature..$^{38}$ In a typical process, $0.5 \mathrm{mM}$ of $\mathrm{H}_{3} \mathrm{BTC}$ was dissolved in $20 \mathrm{ml}$ of water/ethanol mixture $(3: 1 \mathrm{v} / \mathrm{v})$, and
$5 \mathrm{wt} \%$ of graphene oxide was added into the above solution and sonicated for $30 \mathrm{~min}$. Finally, $2 \mathrm{mM}$ of $\left(\mathrm{Ce}\left(\mathrm{NO}_{3}\right)_{2} \cdot 6 \mathrm{H}_{2} \mathrm{O}\right)$ in $20 \mathrm{ml}$ of water/ethanol mixture $(3: 1 \mathrm{v} / \mathrm{v})$ was added and continued stirring for $30 \mathrm{~min}$. Then, the solution was stabilized in a beaker for a whole night, and the final precipitate was washed several times with ethanol and dried at $80^{\circ} \mathrm{C}$ in the vacuum oven for $12 \mathrm{~h}$. The resultant MOF was named as Ce$\mathrm{MOF} / \mathrm{GO}$. Ce-MOF/CNT and pure Ce-MOF were also prepared with and without CNT, respectively.

\section{Materials characterization}

X-ray diffraction system (Rigaku Smartlab) was used with $\mathrm{Cu}-\mathrm{K} \alpha$ radiation $(\lambda=1.540 \AA)$. Step scanning was done with $2 \theta$ intervals from $6^{\circ}$ to $55^{\circ}$. The surface morphologies of the samples were characterized by using scanning electron microscope (Zeiss Merlin) and transmission electron microscope (Tecnai F30). The $\mathrm{N}_{2}$ isotherm of the samples was measured using by BET ASAP 2020.

\section{Electrochemical measurements}

All the electrochemical measurements were carried out in an electrochemical analyzer (CHI $660 \mathrm{E}$ work station). The potentials were measured concerning $\mathrm{Ag} / \mathrm{AgCl}$ (sat.KCl) as the reference. $\mathrm{Ni}$ foam (purchased from Cabot, USA) and Pt wire were used as the working and counter electrode respectively. The cyclic voltammetry was conducted at various scan rates in the potential range from 0 to $0.5 \mathrm{~V}$. The working electrode was made as follows: in brief, a known amount of active material was dispersed in 5 weight $\%$ of Nafion and ethanol mixture. The total surface area coated with active material was $1 \times 1 \mathrm{~cm}^{2}$. The mass of the active material of electrode was $2 \mathrm{mg} \mathrm{cm}^{-2}$. Then, the electrode was dried at $80{ }^{\circ} \mathrm{C}$ for $12 \mathrm{~h}$. Then the electrodes were immersed in $\mathrm{KOH}$ electrolyte for $6 \mathrm{~h}$. Cyclic voltammetry (CV), galvanostatic charge-discharge (GCD) and electrochemical impedance spectroscopy (EIS) studies were carried out in $3 \mathrm{M} \mathrm{KOH}$ and $3 \mathrm{M} \mathrm{KOH}+0.2 \mathrm{M} \mathrm{K}_{3} \mathrm{Fe}(\mathrm{CN})_{6}$ electrolyte solutions under ambient conditions. ECLab software was used for fitting the EIS spectrum.

\section{Results and discussion}

The crystallinity and phase purity of as prepared Ce-MOF, Ce$\mathrm{MOF} / \mathrm{CNT}$, and Ce-MOF/GO samples were investigated using a powder X-ray diffraction. From the Fig. 1(a), all the diffraction peaks of Ce-MOF are sharp and clear, which confirms that the prepared MOFs have excellent crystallinity. All the diffraction peaks were in good agreement with the XRD pattern of previous reports in the literature. ${ }^{38,39}$ Moreover, no peaks associated with any impurity ions were recognized implying that the high phase purity. Furthermore, the diffraction peaks of Ce-MOF/CNT and Ce-MOF/GO shows the Ce-MOF characteristic only, suggesting that the CNT and GO has not affected the crystal structure of the Ce-MOF.

The functional groups of Ce-MOF and its composites are shown in Fig. 1(b). The broader peak from $3300-3400 \mathrm{~cm}^{-1}$ was attributed to the stretching vibrations of $\mathrm{OH}^{-}$, which validates 


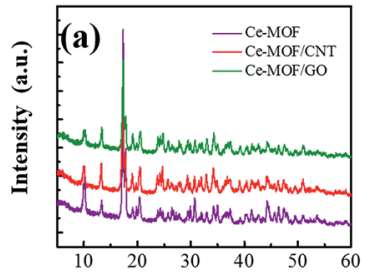

2 Theta (degree)

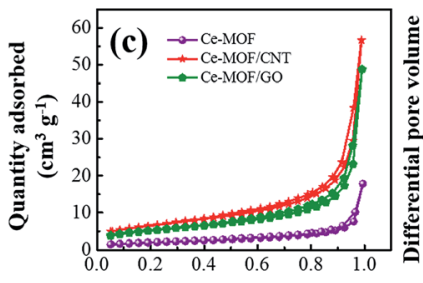

Relative pressure (P/Po)

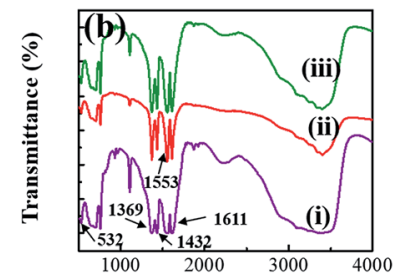

Wavenumber $\left(\mathrm{cm}^{-1}\right)$

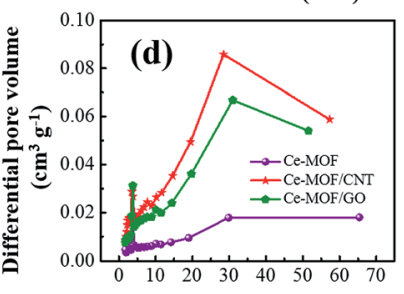

Pore width (nm)
Fig. 1 (a) XRD patterns of Ce-MOF composites (b) FTIR spectrum of (i) Ce-MOF (ii) Ce-MOF/CNT and (iii) Ce-MOF/GO composite (c) nitrogen adsorption-desorption isotherms of Ce-MOF composites and (d) Barrett-Joyner-Halenda (BJH) pore size distribution curves Ce-MOF composites.

that the physically bonded water molecules in MOF during the deprotonation of the solvent. ${ }^{40}$ It is observed that the strong bands appear in the region of 1611-1553 $\mathrm{cm}^{-1}$ and $1432-$ $1369 \mathrm{~cm}^{-1}$ which were assigned to the stretching vibrations $\nu_{\text {as }}\left(-\mathrm{COO}^{-}\right)$and $\nu_{\mathrm{s}}\left(-\mathrm{COO}^{-}\right)$of the carbonate ions. The peak at $532 \mathrm{~cm}^{-1}$ indicates that the stretching vibration of $\mathrm{Ce}-\mathrm{O} .{ }^{41} \mathrm{It}$ could be seen that the same characteristic bands of Ce-MOF appeared in $\mathrm{Ce}-\mathrm{MOF} / \mathrm{GO}$ and $\mathrm{Ce}-\mathrm{MOF} / \mathrm{CNT}$ composites, which suggests that the Ce-MOF has been grafted on the surface of CNT and GO. A similar report has been proposed previously. ${ }^{42}$ To know about the presence of oxygen functional groups in GO, FTIR investigation has been done for bare GO, and the spectrum is shown in Fig. S1. $\dagger$ The strong bands at 1725 and $1624 \mathrm{~cm}^{-1}$ corresponds to $\mathrm{C}=\mathrm{O}$ stretching vibration and $\mathrm{C}=\mathrm{C}$ stretching mode of $\mathrm{COOH}$ groups in GO. There are two weak bands at 1055 and $1217 \mathrm{~cm}^{-1}$, which attributed to the $\mathrm{C}-\mathrm{O}$ bending and $\mathrm{C}-\mathrm{O}$ stretching vibrations in GO. ${ }^{43}$

Brunauer-Emmett-Teller (BET) adsorption/desorption measurements were conducted to investigate the specific surface area and the pore size distribution of the samples. The $\mathrm{N}_{2}$ adsorption isotherms (Fig. 1(c)) are a typical IV-type curve with a distinct hysteresis loop in the range of $0.8-1.0 P / P_{\mathrm{o}}$, indicating the occurrence of mesoporous and macroporous structures. $^{44}$ The BET surface area is measured to be 7.10, 22.86 and $18.83 \mathrm{~m}^{2} \mathrm{~g}^{-1}$ for Ce-MOF, Ce-MOF/CNT and Ce-MOF/GO, respectively. The results were further confirmed with BarrettJoyner-Halenda $(\mathrm{BJH})$ pore size distribution curves which are shown in Fig. 1(d). The BJH curves show peaks centered at around $3.8 \mathrm{~nm}$, which suggests the existence of mesoporous structure in Ce-MOF. The intensity of the centered differential pore volume peak of $\mathrm{Ce}-\mathrm{MOF} / \mathrm{GO}$ is higher than that of other samples, exhibiting an improvement of mesoporous structure. Besides, the other peak of all the samples centered at $\sim 30 \mathrm{~nm}$ indicates the larger pore structure, which mainly comes from voids between the nanorods. ${ }^{45}$ The small intensity peak of Ce-
MOF indicates that the aggregation of nanorods might reduce the voids, surface area and leads to weak electrochemical performance. Though the BET surface area of Ce-MOF/GO is smaller than Ce-MOF/CNT, the large mesoporous structure and the presence of the oxygen functional groups in GO can promote the electron transfer at the electrode/electrolyte interface, thus increase the electrochemical performance.

The morphology of the as-prepared samples was identified with SEM analysis. Fig. 2 shows the SEM images of Ce-MOF/GO and Ce-MOF/CNT. As evidenced from the SEM images, the obtained Ce-MOFs in GO and CNT are uniform sized nanorod structure with diameters of $\sim 150 \mathrm{~nm}$ and lengths of a few micrometer. It could be observed that some of CNT's in CeMOF/CNT (Fig. 2(b)) aggregated due to van der Waal's force of interactions. ${ }^{46}$ The EDS spectrum confirms the presence of $\mathrm{Ce}, \mathrm{C}$ and $\mathrm{O}$ (Fig. 2(c) and (f)), and the mapping images (Fig. S2 and $\mathrm{S} 3 \dagger)$ shows the atomic distribution of $\mathrm{Ce}, \mathrm{C}$ and $\mathrm{O}$ in Ce-MOF composites. From Fig. 2(d) and (e), the Ce-MOF nanorods were deposited on the surface of graphene oxide sheets, and these results were further confirmed with TEM analysis. The wrinkle graphene oxide sheets were decorated by the Ce-MOF nanorods with uniform size (Fig. 3). The deposited nanorods can also act as the spacer and avoid the restacking of GO sheets. On the other hand, the GO sheets can help to prevent the CeMOF nanorods from the aggregation. Both SEM and TEM measurements have showed the high aggregation of CNT as well as nanorods of Ce-MOF in Ce-MOF/CNT sample. The CeMOFs nanorods in Ce-MOF/GO composite are anchored strongly onto the GO sheets with no sign of aggregation. This result shows that there is a strong interaction between the GO sheet and the Ce-MOF nanorods, which will facilitate electron transport through graphene oxide sheets to Ce-MOF nanorods and thereby enhance the electrochemical performance.

To estimate the supercapacitive behavior of the prepared electrodes, cyclic voltammetry (CV), galvanostatic chargedischarge (GCD) and electrochemical impedance spectroscopy (EIS) were examined. Fig. 4 shows the cyclic voltammetry behavior of Ce-MOF and Ce-MOF composites in $3 \mathrm{M} \mathrm{KOH}$, and $3 \mathrm{M} \mathrm{KOH}+0.2 \mathrm{M} \mathrm{K}_{3} \mathrm{Fe}(\mathrm{CN})_{6}$ electrolytes at different scan rates. A pair of redox peaks were discerned in the $\mathrm{CV}$ curves of all

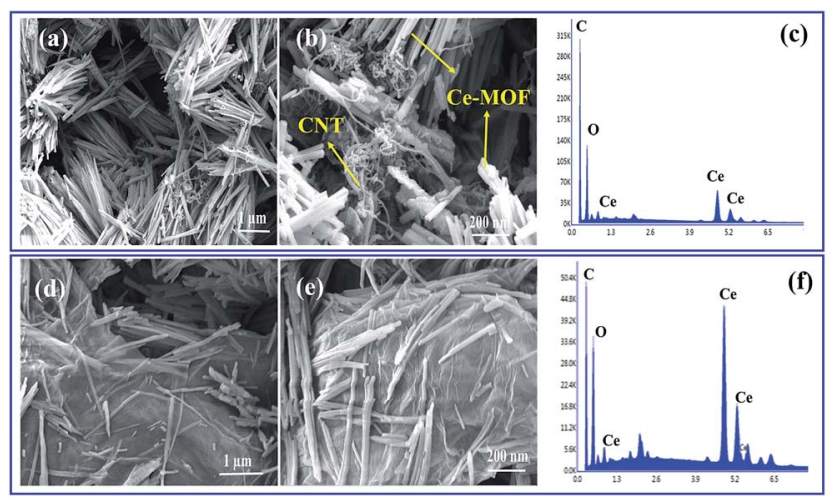

Fig. 2 (a, b) SEM images of Ce-MOF/CNT composite, (c) EDS spectrum of Ce-MOF/CNT (d, e) SEM images of Ce-MOF/GO composite; ( $f$ ) EDS spectrum of Ce-MOF/GO. 

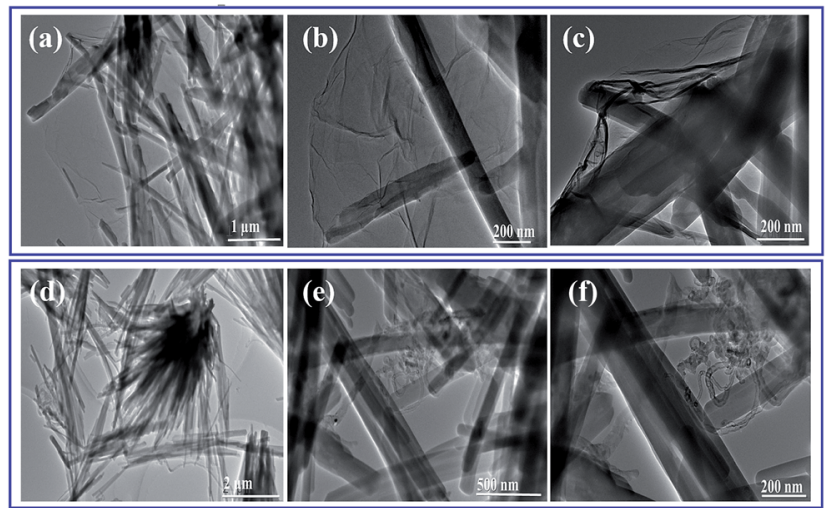

Fig. 3 TEM images of $(a-c) C e-M O F / G O$ and $(d-f) C e-M O F / C N T$ composites.

electrode, which reveals that the pseudocapacitive behavior emerged from the surface redox reactions..$^{47}$ The sharp and well redox peaks of Ce-MOF can be directly attributed to the faradic reactions of the different oxidation states of $\mathrm{Ce}$ and the process can be described by the following equations. A similar process was proposed to explain the redox reaction of Co-MOF. ${ }^{48}$

$$
\begin{aligned}
& \mathrm{Ce}(\mathrm{II})_{\mathrm{s}}+\mathrm{OH}^{-} \leftrightarrow \mathrm{Ce}(\mathrm{II})_{\mathrm{s}}(\mathrm{OH})_{\mathrm{ad}}+\mathrm{e}^{-1} \\
& \mathrm{Ce}(\mathrm{II})_{\mathrm{s}}(\mathrm{OH})_{\mathrm{ad}} \leftrightarrow \mathrm{Ce}(\mathrm{III})_{\mathrm{s}}(\mathrm{OH})_{\mathrm{ad}}+\mathrm{e}^{-1}
\end{aligned}
$$

(a)

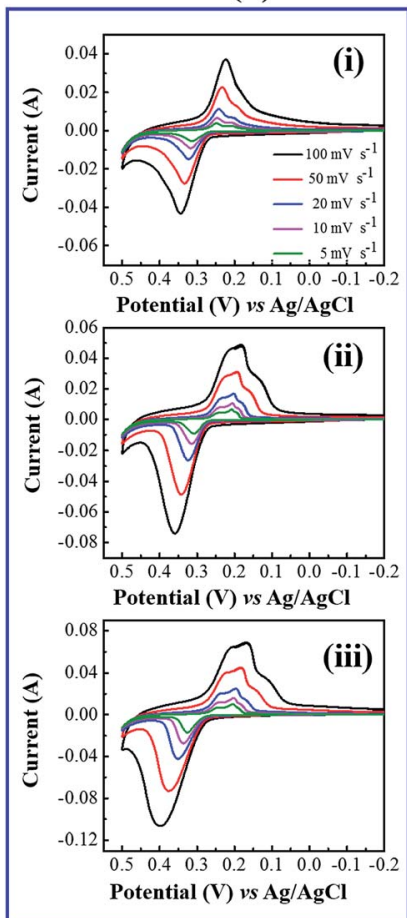

(b)

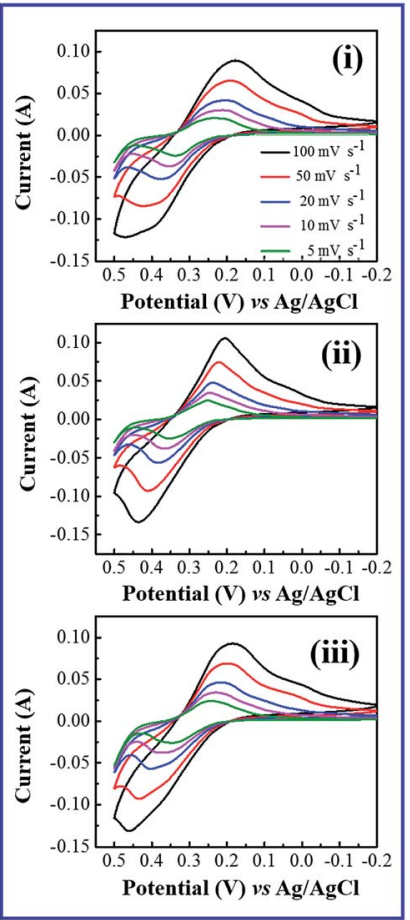

Fig. 4 (a) Cyclic voltammetry response in $3 \mathrm{M} \mathrm{KOH}$ electrolyte (i) $\mathrm{Ce}$ MOF (ii) Ce-MOF/CNT (iii) Ce-MOF/GO composites. (b) Cyclic voltammetry response in $3 \mathrm{M} \mathrm{KOH}+0.2 \mathrm{M} \mathrm{K}_{3}\left(\mathrm{Fe}(\mathrm{CN})_{6}\right)$ electrolyte (i) $\mathrm{Ce}$ MOF (ii) Ce-MOF/CNT (iii) Ce-MOF/GO composites.
The broad redox peaks and the high current response of CV curves in $3 \mathrm{M} \mathrm{KOH}+0.2 \mathrm{M} \mathrm{K}_{3} \mathrm{Fe}(\mathrm{CN})_{6}$ electrolyte suggested more capacitive behavior of the electrodes. This fact can be attributed to the faradic redox reaction of $\mathrm{Fe}(\mathrm{CN})_{6}$ when redox additive was added to $\mathrm{KOH}$ and the possible mechanism is shown as follows, ${ }^{49}$

$$
\left[\mathrm{Fe}(\mathrm{CN})_{6}\right]^{3-}+\mathrm{e}^{-} \leftrightarrow\left[\mathrm{Fe}(\mathrm{CN})_{6}\right]^{4-}
$$

The integral area of the CV curve reflects the amount of real capacitance behavior of the electrodes. ${ }^{50}$ The large area and current of CV curves in $3 \mathrm{M} \mathrm{KOH}+0.2 \mathrm{M} \mathrm{K}_{3} \mathrm{Fe}(\mathrm{CN})_{6}$ electrolyte, which indicates that the $\left[\mathrm{Fe}(\mathrm{CN})_{6}\right]^{3-} /\left[\mathrm{Fe}(\mathrm{CN})_{6}\right]^{4-}$ redox couple directly gives an additional pseudo capacitance contributions to the electrodes. Hence the electrodes exhibited more capacitive behavior.

The galvanostatic charge and discharge (GCD) study is the most direct strategy to characterize the performance of the electrode materials for supercapacitors. Fig. 5(a)-(d) and 6(a)(d) shows the charge-discharge curves of the electrodes at different current densities in $3 \mathrm{M} \mathrm{KOH}$ and $3 \mathrm{M} \mathrm{KOH}+0.2 \mathrm{M}$ $\mathrm{K}_{3} \mathrm{Fe}(\mathrm{CN})_{6}$ electrolyte, respectively. It can be seen that chargedischarge curves of all the electrodes are non-triangle shape and exhibit plateaus at a potential of $\sim 0.2 \mathrm{~V}$ in the discharge curves, indicating the existence of pseudo capacitance behavior ${ }^{51}$ due to

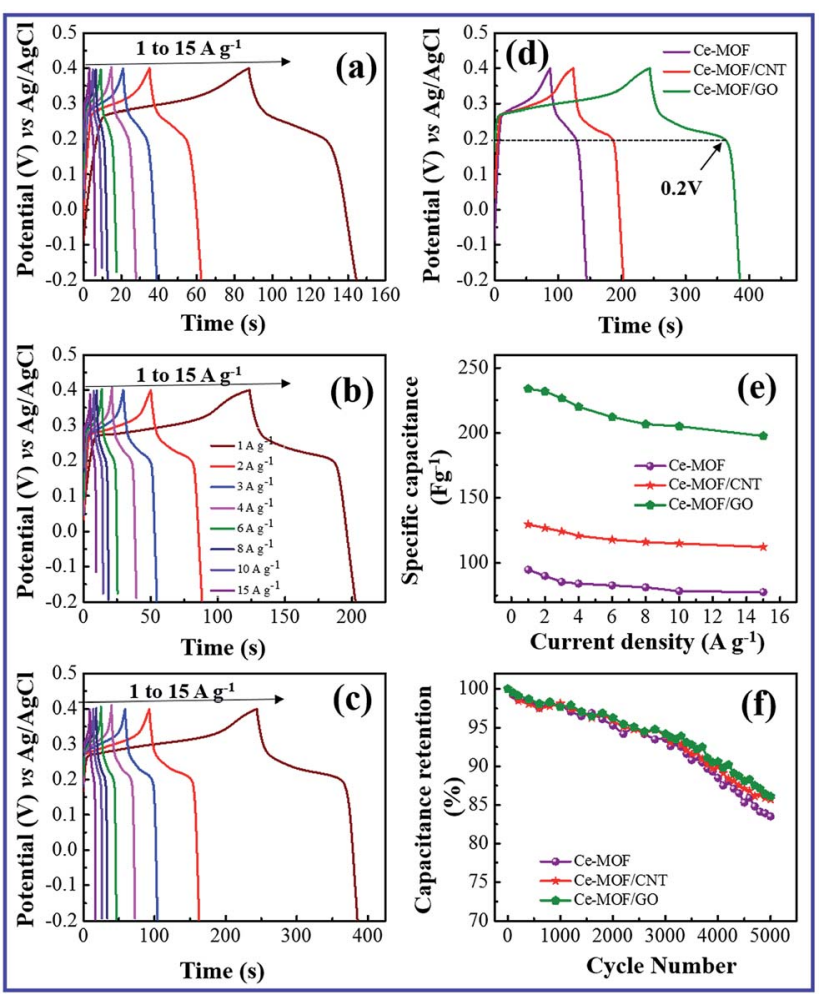

Fig. 5 Galvanostatic charge/discharge behavior in $3 \mathrm{M} \mathrm{KOH}$ electrolyte. (a) Ce-MOF (b) Ce-MOF/CNT (c) Ce-MOF/GO (d) comparison of galvanostatic charge-discharge curve at $1 \mathrm{~A} \mathrm{~g}^{-1}$ current density (e) specific capacitance plot of Ce-MOF composites and ( $f$ ) specific capacitance retention behavior at $3 \mathrm{~A} \mathrm{~g}^{-1}$ current density. 

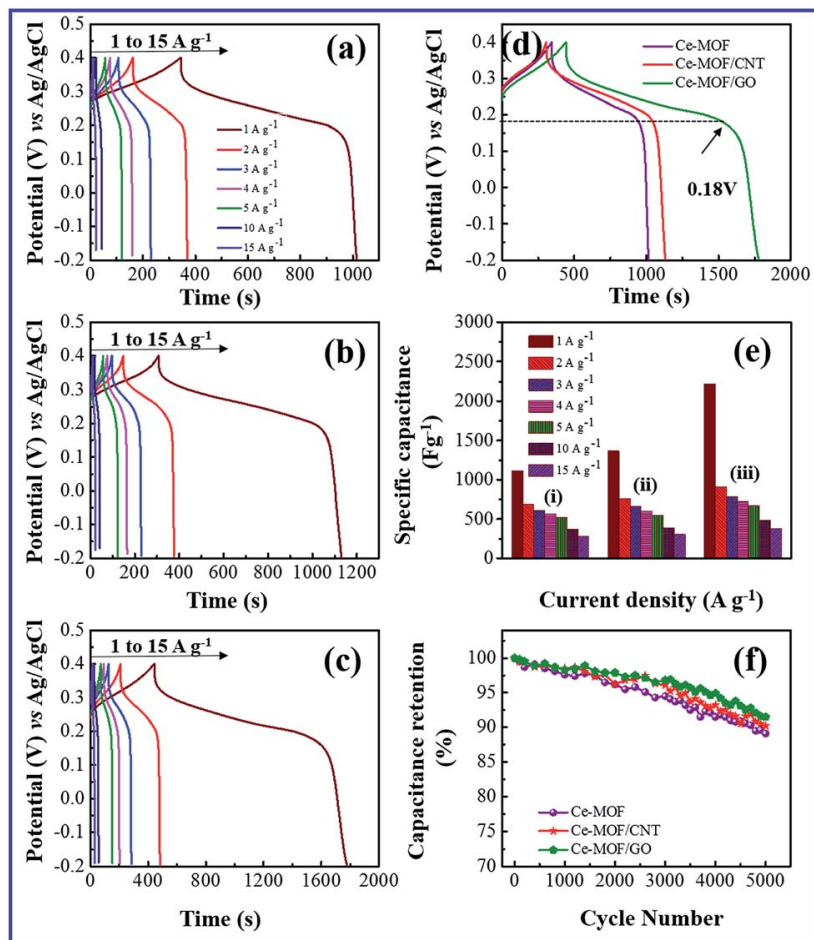

Fig. 6 Galvanostatic charge/discharge behavior in $3 \mathrm{M} \mathrm{KOH}+0.2 \mathrm{M}$ $\mathrm{K}_{3}\left(\mathrm{Fe}(\mathrm{CN})_{6}\right)$ electrolyte. (a) Ce-MOF (b) Ce-MOF/CNT (c) Ce-MOF/GO (d) comparison of galvanostatic charge-discharge curve at $1 \mathrm{~A} \mathrm{~g}^{-1}$ current density (e) specific capacitance plot of Ce-MOF composites and (f) specific capacitance retention behavior at $3 \mathrm{~A} \mathrm{~g}^{-1}$ current density.

the faradic redox reaction of $\mathrm{Ce}^{2+} / \mathrm{Ce}^{3+}$ with $\mathrm{OH}^{-}$, which is also consistent with the CV measurements.

When redox additive was added to $\mathrm{KOH}$, the plateaus potential was shifted to $\sim 0.18 \mathrm{~V}$ in the discharge process (Fig. 6(d)), corresponding to the redox reaction of $\mathrm{K}_{3} \mathrm{Fe}(\mathrm{CN})_{6}$ (ref. 52) which proves that the pseudocapacitance contribution of the redox additive also involved in the total capacitance of the electrode.

The specific capacitance of electrode materials is calculated from galvanostatic discharge curves according to the following equation, ${ }^{53}$

$$
C_{\mathrm{s}}=\frac{i \times \Delta t}{\Delta V \times m}
$$

where $i$ is the constant current (A) of the charge-discharge process; $\Delta t$ is the discharge time (s), $\Delta V$ is the potential window (V) and $m$ is the mass of active material on the electrode (g).

A maximum specific capacitance of 94.8, 129.6 and $233.8 \mathrm{~F}$ $\mathrm{g}^{-1}$ was obtained in $\mathrm{KOH}$ electrolyte for Ce-MOF, Ce-MOF/CNT and Ce-MOF/GO, respectively, at a current density of $1 \mathrm{~A} \mathrm{~g}^{-1}$. Obviously, the specific capacitances of the electrodes were improved after the addition of $\mathrm{K}_{3} \mathrm{Fe}(\mathrm{CN})_{6}$ in $\mathrm{KOH}$, which were calculated as 1116.3, 1367 and $2221.2 \mathrm{~F} \mathrm{~g}^{-1}$ for Ce-MOF, Ce$\mathrm{MOF} / \mathrm{CNT}$, and Ce-MOF/GO, respectively. The reduction in specific capacitance at high current density is probably due to the unfavorable approachability of the electrolyte ions into the inner active sites of the electrode; i.e., the electrodes are inadequate to support complete redox reactions at higher current density because of the lower diffusion rate of $\mathrm{OH}^{-}$ions into the electrodes. ${ }^{54}$ As seen from Fig. 6(a)-(d), the decreased IR drop in the discharge curve suggests that the electrochemical performance is enhanced by $3 \mathrm{M} \mathrm{KOH}+0.2 \mathrm{M} \mathrm{K}_{3} \mathrm{Fe}(\mathrm{CN})_{6}$ electrolyte. Due to higher ionic conductivity and better redox behavior of $\mathrm{K}_{3} \mathrm{Fe}(\mathrm{CN})_{6}$, the electron transportation increases which results in higher specific capacitance. ${ }^{55}$ It should be remarked that a proportion of the redox species in the electrolyte will also participate in the electrode during charge/ discharge process. So, the mass of those redox species should be considered for specific capacitance measurements. ${ }^{56}$ As the evidence of Fig. 5(e) and 6(e), the specific capacitance of CeMOF can be enhanced more significantly with GO than with CNT in both electrolytes. This could be due to the redox activities of the oxygen functional groups which present in GO. The oxygen functional groups in GO such as carbonyl, carboxyl and quinone contribute to the pseudocapacitance. The faradic redox reaction of carboxyl and phenol groups can be expressed as follows, ${ }^{57,58}$

$$
\begin{aligned}
& -\mathrm{COOH}+\mathrm{OH}^{-} \leftrightarrow-\mathrm{COO}+\mathrm{H}_{2} \mathrm{O}+\mathrm{e}^{-} \\
& >\mathrm{C}-\mathrm{OH}+\mathrm{OH}^{-} \leftrightarrow \mathrm{C}=\mathrm{O}+\mathrm{H}_{2} \mathrm{O}+\mathrm{e}^{-}
\end{aligned}
$$

Furthermore, when the current density is increased, the specific capacitance of the electrodes decreases due to the less interaction between electrode and electrolyte ions at higher current densities. In other words, at lower current density the electrolyte ions can easily diffuse into all possible spaces in the electrode surface, which leads to enough insertion reactions. ${ }^{59}$

Long cycle life is one of the major requirements for practical applications of the electrode materials. To study the cyclic stability of the electrodes, an endurance test was conducted using galvanostatic charging/discharging cycles at $3 \mathrm{Ag}^{-1}$. From Fig. 5(f) and 6(f), Ce-MOF/GO electrode shows higher capacitance retention than pure Ce-MOF and Ce-MOF/CNT electrodes, which indicates good rate capability and excellent electrochemical cyclic stability. All the electrodes in $3 \mathrm{M} \mathrm{KOH}+0.2 \mathrm{M}$ $\mathrm{K}_{3} \mathrm{Fe}(\mathrm{CN})_{6}$ electrolyte show good long-term cycle life and exhibit superior electrochemical stability than the pure $\mathrm{KOH}$ electrolyte, which indicates that the addition of $0.2 \mathrm{M} \mathrm{K}_{3} \mathrm{Fe}(\mathrm{CN})_{6}$ to the electrolyte has remarkably enhanced the specific capacitance of electrodes, but also improved the cyclic stability. Coulombic efficiency is an essential circumstance which represents the stability of electrode materials through the charge-discharge process. The coulombic efficiency of electrode is estimated according to the formula, ${ }^{60}$

$$
\eta=\frac{t_{\mathrm{d}}}{t_{\mathrm{c}}} \times 100
$$

where, $t_{\mathrm{d}}$ is discharge time (s) and $t_{\mathrm{c}}$ is charging time (s). As seen in Fig. 7(a), the initial coulombic efficiencies of all electrodes are low, which is due to agglomeration of Ce-MOF nanorods and re-stacking of GO and CNT. Compared with $3 \mathrm{M} \mathrm{KOH}$ electrolyte, the coulombic efficiencies of all the three electrodes are higher in $3 \mathrm{M} \mathrm{KOH}+0.2 \mathrm{M} \mathrm{K}_{3} \mathrm{Fe}(\mathrm{CN})_{6}$ electrolyte (Fig. 7(c)). 


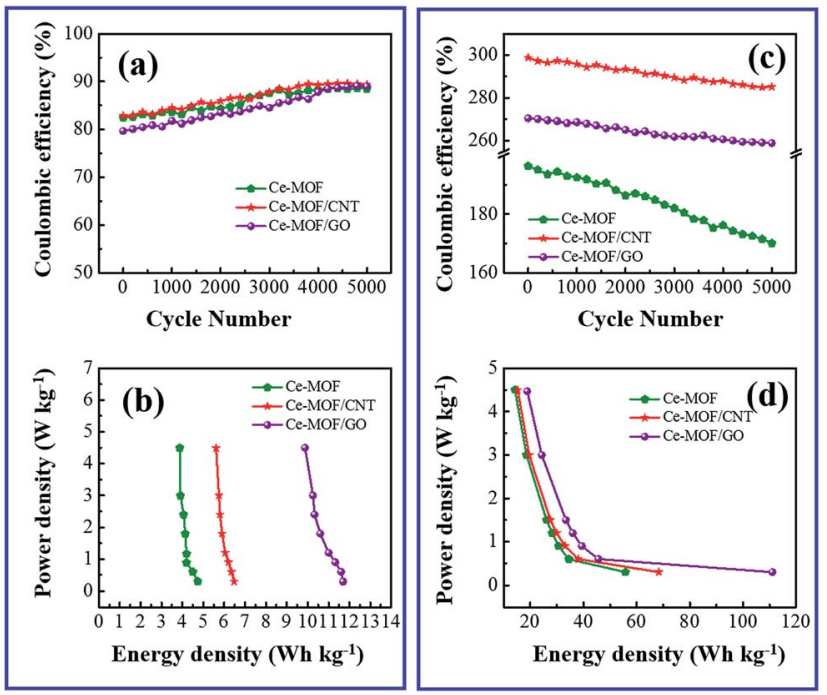

Fig. 7 (a) Coulombic efficiency in $3 \mathrm{M} \mathrm{KOH}$ electrolyte (b) Ragone plot of Ce-MOF composite in $3 \mathrm{M} \mathrm{KOH}$ electrolyte (c) coulombic efficiency in $3 \mathrm{M} \mathrm{KOH}+0.2 \mathrm{M} \mathrm{K}_{3}\left(\mathrm{Fe}(\mathrm{CN})_{6}\right)$ electrolyte (d) Ragone plot of Ce-MOF composite in $3 \mathrm{M} \mathrm{KOH}+0.2 \mathrm{M} \mathrm{K}_{3}\left(\mathrm{Fe}(\mathrm{CN})_{6}\right)$ electrolyte.

When the electrode is charged from -0.2 to $0.4 \mathrm{~V}$, only Ce-MOF and the composites are involved in redox process (Ce(II) to $\mathrm{Ce}(\mathrm{III}))$. During reverse potential $(0.4$ to $-0.2 \mathrm{~V})$, the transformation of $\mathrm{Ce}(\mathrm{III})$ to $\mathrm{Ce}(\mathrm{II})$ takes place. Besides, hexacyanoferrate(III) ion also undergoes redox process; i.e., there are two faradic redox reactions of $\mathrm{Fe}(\mathrm{CN})_{6}{ }^{3-} / \mathrm{Fe}(\mathrm{CN})_{6}{ }^{4-}$ occurring simultaneously during the discharge process. ${ }^{61}$ Thus, the discharge time is much longer than charging time, resulting in higher coulombic efficiency.

The morphology of Ce-MOF, Ce-MOF/GO and Ce-MOF/CNT electrodes were studied before and after 5000 cycles at a current density of $3 \mathrm{~A} \mathrm{~g}^{-1}$ in $3 \mathrm{M} \mathrm{KOH}$. As shown in Fig. S4, $\dagger$ there were no significant changes in electrode's morphology even after long charging/discharging process indicates the good stability.

Fig. 7(b) and (d) shows the energy and power density of CeMOF composites in $3 \mathrm{M} \mathrm{KOH}$ and $3 \mathrm{M} \mathrm{KOH}+0.2 \mathrm{M}$ $\mathrm{K}_{3}\left(\mathrm{Fe}(\mathrm{CN})_{6}\right)$ electrolytes, and it is calculated by the following equations, ${ }^{62}$

$$
\begin{gathered}
E=\frac{1}{2} C V^{2} \times \frac{1}{3600} \\
P=\frac{E}{t} \times 3600
\end{gathered}
$$

Maximum energy density and power density of $11.96 \mathrm{~W} \mathrm{~h} \mathrm{~kg}^{-1}$ and $4.497 \mathrm{~kW} \mathrm{~kg}^{-1}$ was obtained for Ce-MOF/GO electrode, respectively. The energy density of Ce-MOF/GO is higher than that of Ce-MOF and Ce-MOF/CNT, which mainly benefits from the high specific capacitance. The energy density of Ce-MOF/GO was improved to $111.05 \mathrm{~W} \mathrm{~h} \mathrm{~kg}^{-1}$ after addition of $0.2 \mathrm{M} \mathrm{K}_{3} \mathrm{Fe}(\mathrm{CN})_{6}$ to $\mathrm{KOH}$, implying that Ce-MOF/GO electrode in $3 \mathrm{M} \mathrm{KOH}+0.2 \mathrm{M} \mathrm{K}_{3} \mathrm{Fe}(\mathrm{CN})_{6}$ electrolyte could be used in high performance supercapacitor device.
Electrochemical impedance spectroscopy was investigated to examine the frequency dependent charge transport phenomenon in the electrodes. Fig. 8(a) and (c) shows the Nyquist plot of Ce-MOF composite electrodes measured with an AC perturbation of $0.1 \mathrm{~V}$ in the frequency range from $1 \mathrm{~Hz}$ to $10^{5} \mathrm{~Hz}$. A semicircle region could not be recognized at high frequency region which is attributed to the low faradic charge transfer resistance $^{4}$ and the vertical line at low frequency region shows the ideal capacitive behavior of the electrodes. ${ }^{63}$ It is noticed that the vertical line of Ce-MOF/GO electrode at low frequency is approaching to the imaginary axis, indicating better pseudocapacitance behavior than other electrodes, which is probably due to the pseudocapacitance contribution of oxygen functional groups in GO. Bode plot phase angles as function of the frequency of the electrodes in $3 \mathrm{M} \mathrm{KOH}$ and $3 \mathrm{M} \mathrm{KOH}+0.2 \mathrm{M}$ $\mathrm{K}_{3} \mathrm{Fe}(\mathrm{CN})_{6}$ electrolytes are shown in Fig. $8(\mathrm{~b})$ and (d), respectively. The phase angles of all the electrodes lie in the range of $50-70^{\circ}$ at low frequency $(<100 \mathrm{~Hz})$, which suggests the redox and ideal capacitive behavior of the electrodes. ${ }^{64}$ The phase angle is slightly higher for Ce-MOF/GO in both electrolytes, probably due to the broader pseudocapacitance behavior, which is consistent with the results obtained from $\mathrm{CV}$ and GCD measurements. When the frequency is increased $\left(100-10^{5} \mathrm{~Hz}\right)$, the phase angle decreases rapidly, and it reached $\sim$ zero at the frequency region $10^{4}-10^{5} \mathrm{~Hz}$. This fact can be associated to the less adsorption of the electrolyte ions onto the electrode surface, which leads to less accessible sites in the electrode. Therefore, the resistive component is dominant rather than the capacitive behavior, which reveals phase angle of $\sim$ zero at the high frequency region.

The Ce-MOF/GO composite electrode exhibited an enhanced electrochemical performance in $3 \mathrm{M} \mathrm{KOH}+0.2 \mathrm{M} \mathrm{K}_{3} \mathrm{Fe}(\mathrm{CN})_{6}$ electrolyte, and this can be attributed to the following features. (1)
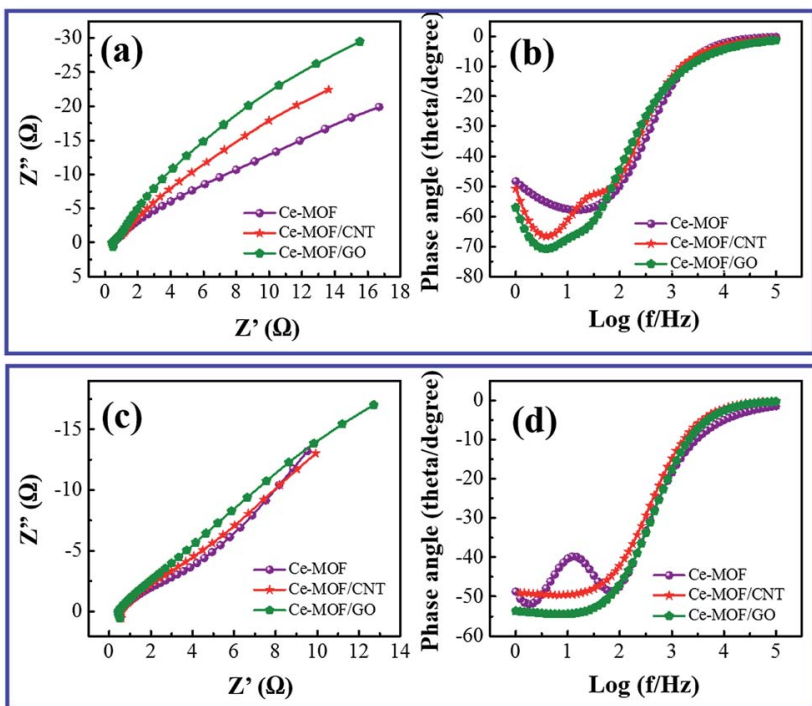

Fig. 8 (a) Nyquist plot and (b) Bode phase angle of Ce-MOF composites in $3 \mathrm{M} \mathrm{KOH}$ electrolyte. (c) Nyquist plot and (d) Bode phase angle of Ce-MOF composites in $3 \mathrm{M} \mathrm{KOH}+0.2 \mathrm{M} \mathrm{K}_{3}\left(\mathrm{Fe}(\mathrm{CN})_{6}\right)$ electrolyte. 

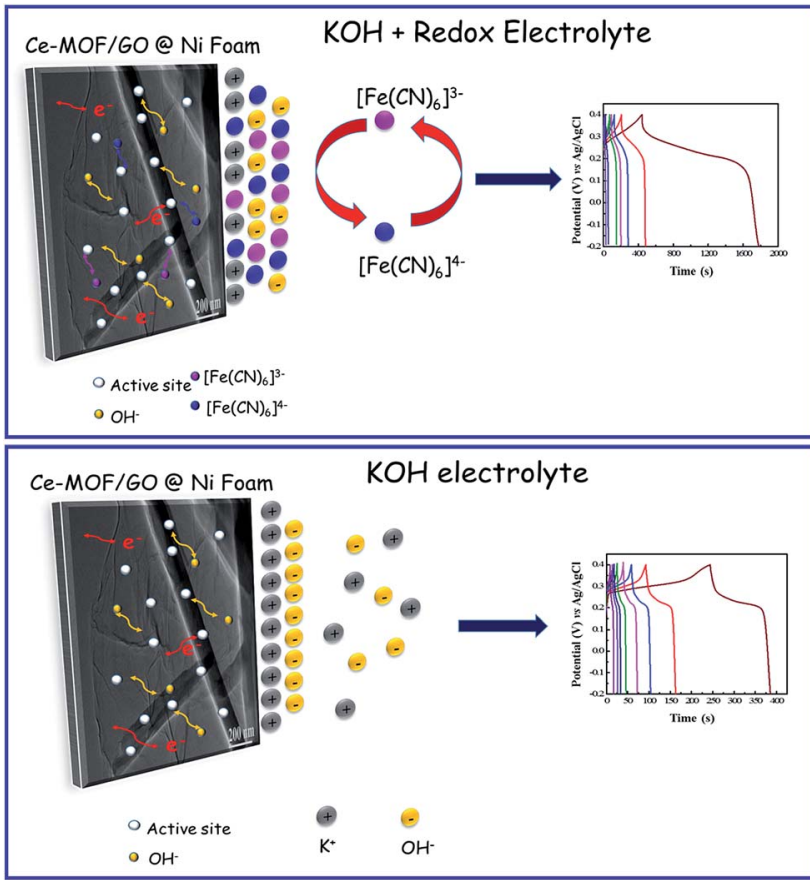

Fig. 9 Charge transport mechanism of Ce-MOF/GO composite.

Graphene oxide sheets could prevent the aggregations of the CeMOF nanorods and anchored directly on the GO sheets, which makes good contact between the electrolyte and electrode surface. (2) The presence of the oxygen functional groups were involved for redox reaction with electrolyte ions and enhanced pseudocapacitance. (3) The large mesoporous structure of CeMOF/GO could facilitate the ions transfer in electrode/ electrolyte interfaces. (4) Redox reaction could be enhanced by the redox additive species in the electrolyte (Fig. 9). The overall results suggest that the synthesized Ce-MOF/GO composite could be used for high performance supercapacitor electrode material.

\section{Conclusions}

In summary, we have prepared Ce-MOF based composites by wet chemical route and studied their electrochemical performance towards the supercapacitor electrodes. A maximum specific capacitance of $2221.2 \mathrm{~F} \mathrm{~g}^{-1}$ and energy density of 111.05 $\mathrm{W} \mathrm{h} \mathrm{kg}^{-1}$ have been obtained for Ce-MOF/GO composite at a current density of $1 \mathrm{~A} \mathrm{~g}^{-1}$ in $3 \mathrm{M} \mathrm{KOH}+0.2 \mathrm{M} \mathrm{K}_{3} \mathrm{Fe}(\mathrm{CN})_{6}$ electrolyte. This enhanced electrochemical behavior due to the large mesoporous structure of Ce-MOF and pseudocapacitance contribution of graphene oxide sheet. The excellent long term stability of Ce-MOF/GO composite showed that the promising electrode material towards supercapacitor applications.

\section{Conflicts of interest}

There are no conflicts to declare.

\section{Acknowledgements}

This work was supported by National Natural Science Foundation of China (Project No. 51505209) and Shenzhen Science and Technology Innovation Committee (Projects No. JCYJ20170412154426330 and KQTD2015071710313656). Fei Wang is also supported by Guangdong Natural Science Funds for Distinguished Young Scholar (Project No. 2016A030306042) and the Guangdong Special Support Program (Project No. 2015TQ01X555).

\section{Notes and references}

1 J. Zhao, Y. Gao and A. F. Burke, J. Power Sources, 2017, 363, 327-340.

2 Y. G. Zhu, G. S. Cao, C. Y. Sun, J. Xie, S. Y. Liu, T. J. Zhu, X. B. Zhao and H. Y. Yang, RSC Adv., 2013, 3, 19409-19415.

3 H. Heydari, S. E. Moosavifard, S. Elyasi and M. Shahraki, Appl. Surf. Sci., 2017, 394, 425-430.

4 R. Ramachandran, M. Saranya, P. Kollu, B. P. C. Ragupathy, S. K. Jeong and A. N. Grace, Electrochim. Acta, 2015, 178, 647657.

5 M. Lian, X. Wu, Q. Wang, W. Zhang and Y. Wan, Ceram. Int., 2017, 43, 9877-9883.

6 Y. Zhan, Y. Meng, N. Yan, Y. Li, D. Wei and X. Tao, J. Appl. Polym. Sci., 2017, 134, 45566.

7 Q. Meng, K. Cai, Y. Chen and L. Chen, Nano Energy, 2017, 36, 268-285.

8 A. Afzal, F. A. Abuilaiwi, A. Habib, M. Awais, S. B. Waje and M. A. Atieh, J. Power Sources, 2017, 352, 174-186.

9 J. Huang, J. Wang, C. Wang, H. Zhang, C. Lu and J. Wang, Chem. Mater., 2015, 27(6), 2107-2113.

10 R. Ramachandran, M. Saranya, A. N. Grace and F. Wang, RSC Adv., 2017, 7, 2249-2257.

11 M. Yang, K. G. Lee, S. J. Lee, S. B. Lee, Y. K. Han and B. G. Choi, ACS Appl. Mater. Interfaces, 2015, 7, 22364-22371.

12 H. Wang, J. Liu, Z. Chen, S. Chen, T. C. Sum, J. Lin and Z. X. Shen, Electrochim. Acta, 2017, 230, 236-244.

13 W. Zhang, Y. Ma, Z. Yang, X. Tang, X. Li, G. He, Y. Cheng, Z. Fang, R. He and Y. Zhang, J. Alloys Compd., 2017, 712, 704-713.

14 Y. Zhao, Z. Song, X. Li, Q. Sun, N. Cheng, S. Lawes and X. Sun, Energy Storage Materials, 2016, 2, 35-62.

15 W. Xia, A. Mahmood, R. Zou and Q. Xu, Energy Environ. Sci., 2015, 8, 1837-1866.

16 R. R. Salunkhe, Y. V. Kaneti, J. Kim, J. H. Kim and Y. Yamauchi, Acc. Chem. Res., 2016, 49, 2796-2806.

17 B. Liu, H. Shioyama, T. Akita and Q. Xu, J. Am. Chem. Soc., 2008, 130, 5390-5539.

18 J. Kim, C. Young, J. Lee, M. S. Park, M. Shahabuddin, Y. Yamauchi and J. H. Kim, Chem. Commun., 2016, 52, 13016-13019.

19 L. Wang, Y. Han, X. Feng, J. Zhou, P. Qi and B. Wang, Coord. Chem. Rev., 2016, 307, 361-381.

20 J. Yang, Z. Ma, W. Gao and M. Wei, Chem.-Eur. J., 2017, 23, 631-636. 
21 Y. Jiao, J. Pei, D. Chen, C. Yan, Y. Hu, Q. Zhang and G. Chen, J. Mater. Chem. A, 2017, 5, 1094-1102.

22 Y. Jiao, J. Pei, C. Yan, D. Chen, Y. Hu and G. Chen, J. Mater. Chem. A, 2016, 4, 13344-13351.

23 M. L. Yue, Y. F. Jiang, L. Zhang, C. Y. Yu, K. Y. Zou and Z. X. Li, Chem.-Eur. J., 2017, 13, 1-15.

24 X. Wang, X. Liu, H. Rong, Y. Song, H. Wen and Q. Liu, RSC Adv., 2017, 7, 29611-29617.

25 J. Kim, C. Young, J. Lee, Y. U. Heo, M. S. Park, M. S. A. Hossain, Y. Yamauchi and J. H. Kim, J. Mater. Chem. A, 2017, 5, 15065-15072.

26 J. Yang, C. Zheng, P. Xiong, Y. Li and M. Wei, J. Mater. Chem. A, 2014, 2, 19005-19010.

27 P. Srimuk, S. Luanwuthi, A. Krittayavathananon and M. Sawangphruk, Electrochim. Acta, 2015, 157, 69-77.

28 A. Hosseininan, A. Amjad, R. H. Khanmiri, E. G. Kalhor, M. Babazadeh and E. Vessally, J. Mater. Sci.: Mater. Electron., 2017, 28, 18040-18048.

29 Y. Liu, G. Li, Y. Ying and X. Peng, ACS Appl. Mater. Interfaces, 2017, 9(16), 14043-14050.

30 P. Wen, P. Gong, J. Sun, J. Wang and S. Yang, J. Mater. Chem. A, 2015, 3, 13874-13883.

31 M. Saraf, R. Rajak and S. M. Mobin, J. Mater. Chem. A, 2016, 4, 16432-16445.

32 D. Xu, X. N. Sun, W. Hu and X. Y. Chen, J. Power Sources, 2017, 357, 107-116.

33 S. T. Senthilkumar, R. Kalaiselven and J. S. Melo, J. Mater. Chem. A, 2013, 1, 12386-12394.

34 H. Yu, L. Fan, J. Wu, Y. Lin, M. Huang, J. Lin and Z. Lan, RSC Adv., 2012, 2, 6736-6740.

35 K. Chen, F. Liu, D. Xue and S. Komarneni, Nanoscale, 2015, 7, 432-439.

36 J. Kim, J. H. Kim and K. Ariga, Joule, 2017, 1, 739-768.

37 Q. Wang, Y. F. Nie, Z. H. Xiao, X. Y. Chen and Z. J. Zhang, J. Electroanal. Chem., 2016, 770, 62-72.

38 Y. Xiong, S. Chen, F. Ye, L. Su, C. Zhang, S. Shen and S. Zhao, Chem. Commun., 2015, 51, 4635-4638.

39 K. Liu, H. You, G. Jia, Y. Zheng, Y. Huang, Y. Song, M. Yang, L. Zhang and H. Zhang, Cryst. Growth Des., 2010, 10(2), 790797.

40 S. Bennabi and M. Belbachir, Adv. Mater. Lett., 2015, 6(3), 271-277.

41 X. Zhang, F. Hou, H. Li, Y. Yang, Y. Wang, N. Liu and Y. Yang, Microporous Mesoporous Mater., 2017, 259, 211-219.

42 T. Balamurugan and S. Berchmans, RSC Adv., 2015, 5, 50470-50477.
43 R. Ramachandran, S. Felix, G. M. Joshi, B. P. C. Ragupathy, S. K. Jeong and A. N. Grace, Mater. Res. Bull., 2013, 48, 3834-3842.

44 G. Zhou, J. Zhu, Y. J. Chen, L. Mei, X. C. Duan, G. H. Zhang, L. B. Chen, T. H. Wang and B. G. Lu, Electrochim. Acta, 2014, 123, 450-455.

45 Z. Gao, F. Wang, J. Chang, D. Wu, X. Wang, X. Wang, F. Xu, S. Gao and K. Jiang, Electrochim. Acta, 2014, 133, 325-334.

46 A. A. Johm, A. P. Subramanian, M. V. Vellayappan, A. Balaji, H. Mohandas and S. K. Jaganathan, Int. J. Nanomed., 2015, 10, 4267-4277.

47 L. Wang, Z. H. Dong, Z. G. Wang, F. X. Zhang and J. Jin, Adv. Funct. Mater., 2013, 13, 2758-2764.

48 L. Kang, S. X. Sun, L. B. Kong, J. W. Lang and Y. C. Luo, Chin. Chem. Lett., 2014, 25, 957-961.

49 K. Chen, S. Song and D. Xue, RSC Adv., 2014, 4, 23338-23343. 50 L. Banda, D. Aradilla, A. Benayad, Y. Chenavier, B. Daffos, L. Dubois and F. Duclairoir, J. Power Sources, 2017, 360, 538-547.

51 X. Liu, C. Shi, C. Zhai, M. Cheng, Q. Liu and G. Wang, ACS Appl. Mater. Interfaces, 2016, 8, 4585-4591.

52 C. Zhao, W. Zheng, X. Wang, H. Zhang, X. Cui and H. Wang, Sci. Rep., 2013, 3, 2986.

53 R. Kumuthini, R. Ramachandran, H. A. Therese and F. Wang, J. Alloys Compd., 2017, 705, 624-630.

54 R. Wang, P. Wang, X. Yan, J. Lang, C. Peng and Q. Xue, ACS Appl. Mater. Interfaces, 2012, 4, 5800-5806.

55 E. Feng, G. Ma, K. Sun, Q. Yang, H. Peng and Z. Lei, RSC Adv., 2016, 6, 75896-75904.

56 B. Akinwolemiwa, C. Peng and G. Z. Chen, J. Electrochem. Soc., 2015, 162(5), A5054-A5059.

57 R. Ramachandran, M. Saranya, V. Venugopal, B. P. C. Ragupathy, S. K. Jeong and A. N. Grace, Appl. Energy, 2015, 153, 22-31.

58 J. Yan, Q. Wang, T. Wei, L. Jiang, M. Zhang, X. Jing and Z. Fan, ACS Nano, 2014, 8, 4720-4729.

59 R. Kotz and M. Carlen, Electrochim. Acta, 2000, 45, 24832498.

60 Q. Wang, L. Jiao, H. Du, Y. Si, Y. Wang and H. Yuan, J. Mater. Chem., 2012, 22, 21387-21391.

61 L. H. Su, X. G. Zhang, C. H. Mi, B. Gao and Y. Lin, Phys. Chem. Chem. Phys., 2009, 11, 2195-2202.

62 J. Wen, S. Li, B. Li, Z. Song, H. Wang, R. Xiong and G. Fang, J. Power Sources, 2015, 284, 279-286.

63 A. Liu, H. Che, Y. Mao, Y. Wang, J. Mu, C. Xu, Y. Bai, X. Zhang and G. Wang, Ceram. Int., 2016, 42, 11435-11441.

64 N. S. Arul, D. Mangalaraj, R. Ramachandran, A. N. Grace and J. I. Han, J. Mater. Chem. A, 2015, 3, 15248-15258. 